Article

\title{
Theoretical Study on the Electronic Structure and Magnetic Properties Regulation of Janus Structure of $\mathbf{M}^{\prime} \mathbf{M C O}_{2}$ 2D MXenes
}

\author{
Panpan Gao ${ }^{1,2}$, Minhui Song ${ }^{1}$, Xiaoxu Wang ${ }^{1}$, Qing Liu ${ }^{1,2,3}$, Shizhen He ${ }^{1}$, Ye Su ${ }^{1, *}$ and Ping Qian ${ }^{1,2, *}$ \\ 1 Beijing Advanced Innovation Center for Materials Genome Engineering, University of Science and \\ Technology Beijing, Beijing 100083, China; gaopanpan@ustb.edu.cn (P.G.); mhuisong@163.com (M.S.); \\ wangxx@dp.tech (X.W.); liuqing6903@163.com (Q.L.); hsz0430@163.com (S.H.) \\ 2 School of Mathematics and Physics, University of Science and Technology Beijing, Beijing 100083, China \\ 3 Department of Physics, National University of Singapore, Singapore 117551, Singapore \\ * Correspondence: suyechina@163.com (Y.S.); qianping@ustb.edu.cn (P.Q.)
}

check for updates

Citation: Gao, P.; Song, M.; Wang, X.; Liu, Q.; He, S.; Su, Y.; Qian, P. Theoretical Study on the Electronic Structure and Magnetic Properties Regulation of Janus Structure of $\mathrm{M}^{\prime} \mathrm{MCO}_{2} 2 \mathrm{D}$ MXenes. Nanomaterials 2022, 12, 556. https://doi.org/ 10.3390/nano12030556

Academic Editor: Francesc Viñes Solana

Received: 8 January 2022

Accepted: 2 February 2022

Published: 6 February 2022

Publisher's Note: MDPI stays neutral with regard to jurisdictional claims in published maps and institutional affiliations.

Copyright: () 2022 by the authors Licensee MDPI, Basel, Switzerland. This article is an open access article distributed under the terms and conditions of the Creative Commons Attribution (CC BY) license (https:// creativecommons.org/licenses/by/ $4.0 /)$.

\begin{abstract}
Motivated by the recent successful synthesis of Janus monolayer of transition metal (TM) dichalcogenides, MXenes with Janus structures are worthy of further study, concerning its electronic structure and magnetic properties. Here, we study the effect of different transition metal atoms on the structure stability and magnetic and electronic properties of $\mathrm{M}^{\prime} \mathrm{MCO}_{2}\left(\mathrm{M}^{\prime}\right.$ and $\mathrm{M}=\mathrm{V}, \mathrm{Cr}$ and $\left.\mathrm{Mn}\right)$. The result shows the output magnetic moment is contributed mainly by the d orbitals of the $\mathrm{V}, \mathrm{Cr}$, and $\mathrm{Mn}$ atoms. The total magnetic moments of ferromagnetic (FM) configuration and antiferromagnetic (AFM) configuration are affected by coupling types. FM has a large magnetic moment output, while the total magnetic moments of AFM2's (intralayer AFM/interlayer FM) configuration and AFM3's (interlayer AFM/intralayer AFM) configuration are close to 0 . The band gap widths of $\mathrm{VCrCO}_{2}$, $\mathrm{VMnCO}_{2}, \mathrm{CrMnCO}_{2}, \mathrm{~V}_{2} \mathrm{CO}_{2}$, and $\mathrm{Cr}_{2} \mathrm{CO}_{2}$ are no more than $0.02 \mathrm{eV}$, showing metallic properties, while $\mathrm{Mn}_{2} \mathrm{CO}_{2}$ is a semiconductor with a $0.7071 \mathrm{eV}$ band gap width. Janus MXenes can regulate the size of band gap, magnetic ground state, and output net magnetic moment. This work achieves the control of the magnetic properties of the available 2D materials, and provides theoretical guidance for the extensive design of novel Janus MXene materials.
\end{abstract}

Keywords: janus; MXenes; magnetic properties; DFT

\section{Introduction}

Over the past decade, the two-dimensional (2D) materials have received significant interest since the discovery of graphene [1-3]. Compared with bulk materials, more atoms on the surface of 2D materials are exposed, which is caused by reduced dimensionality. This improves the utilization rates of atoms and makes regulation of band structure and electronic properties easier, thus enabling MXenes to exhibit novel physical and chemical properties [4-6]. Recently, a new family of 2D transition metal (TM) carbides and nitrides, MXenes, has received more and more attention $[7,8]$. MXenes have the general formula $M_{n+1} X_{n} T_{x}$, where $M$ stands for early TM, $X$ represents $C$ or $N, T_{x}$ indicates the surface functional groups $\mathrm{O}, \mathrm{OH}$, or $\mathrm{F}$, and $\mathrm{n}=1,2$, or 3 [9,10]. Usually, MXenes are synthesized by selective etching A layers (A is an element from the A-group 13 or 14) in the MAX phase, using hydrofluoric acid (HF) solutions [11-13]. Sue to their excellent electrical [14], optical [15-18], and mechanical properties [19], MXenes have been widely applied in electronic devices [20], catalysis [21-24], magnetic storage [25], energy conversion, and storage systems [26-28]. Thus far, more than 30 kinds of MXenes have been synthesized in experiments, and more kinds of materials have been theoretically predicted $[29,30]$.

The electronic and optical properties of MXenes with symmetrical configuration have been extensively studied. Previous theoretical investigations have shown that, without 
surface functionalization, $\mathrm{Cr}_{2} \mathrm{C}$ is half metallic and ferromagnetic (FM) configuration [31], $\mathrm{V}_{2} \mathrm{C}$ exhibits metallic and antiferromagnetic (AFM) configuration [32], and $\mathrm{Ti}_{n+1} \mathrm{C}_{n}$ and $\mathrm{Ti}_{\mathrm{n}+1} \mathrm{~N}_{\mathrm{n}}(\mathrm{n}=1-9)$ show magnetic configuration [33]. While functionalized MXenes alter magnetism, others, such as $\mathrm{Cr}_{2} \mathrm{CX}_{2}(\mathrm{X}=\mathrm{OH}, \mathrm{O}$ and $\mathrm{F}), \mathrm{V}_{2} \mathrm{CX}_{2}(\mathrm{X}=\mathrm{F}, \mathrm{OH})$, and $\mathrm{Ti}_{2} \mathrm{CO}_{2}$, are semiconductors [31-35]. Structural symmetry is a key factor in determining the electronic properties of 2D materials [36,37]. If structural symmetry is broken, it is desirable for 2D materials to have electronic and magnetic properties.

Inspired by the successful synthesis of Janus monolayers of TM dichalcogenides [38], MXenes with Janus structures are worth studying further, especially concerning their electronic structures and magnetic properties. Janus refers to MXenes that break the symmetry through asymmetric surface functional groups or different types of TM elements [39]. A previous report has theoretically studied the electronic and magnetic properties of Janus MXenes; it indicated that, by selecting an appropriate terminal group of upper and lower surfaces, the band gap of Janus MXenes can be successfully adjusted to different regions [40]. Therefore, we consider that different TM atoms may also regulate the charge and chemical environment around the atom, which causes Janus MXenes to exhibit significantly different electronic and magnetic properties.

In this paper, using first-principles calculations, we employed $\mathrm{M}^{\prime} \mathrm{MCO}_{2}\left(\mathrm{M}^{\prime}\right.$ and $\mathrm{M}$ stands for $\mathrm{V}, \mathrm{Cr}$, and $\mathrm{Mn}$ ) configurations to investigate the effect of different types of TM on the structure and the magnetic and electronic properties under the same functional groups. We constructed different magnetic configurations (nonmagnetic (NM), FM, and AFM) for each $\mathrm{M}^{\prime} \mathrm{MCO}_{2}$ structure, researched their magnetic properties, and screened out the magnetic ground state. Then, we studied the electronic structure of the magnetic ground state. The results showed that Janus MXenes can adjust the band gap, the magnetic ground state, and the net output magnetic moments, which is a very good control method. Due to its asymmetric structure, Janus MXenes can flexibly control the magnetism of a system by applying small electric fields. This work provides theoretical guidance for the realization of the magnetic controllability of MXene materials.

\section{Materials and Methods}

All calculations were carried out using the Vienna ab initio simulation package (VASP), based on density functional theory (DFT) [41,42]. The generalized gradient approximation (GGA), with the Perdew-Burke-Ernzerhof (PBE) functional, was used for the exchange and correlation functional $[43,44]$. Interactions between electrons and nuclei were described by the projector augmented wave (PAW) method [45]. A plane wave kinetic energy cutoff $600 \mathrm{eV}$ was employed. The convergence criteria of total energy and atomic force for each atom were set to $10^{-5} \mathrm{eV}$ per unit cell and $10^{-4} \mathrm{eV} / \AA$, respectively.

To account for the energy of localized 3D orbitals of TM atoms properly, the Hubbard " $\mathrm{U}$ " correction was employed within the rotationally invariant DFT + U approach proposed [46]. The spin-polarized DFT + U correction [47,48] was applied to strongly correlated $\mathrm{Cr}, \mathrm{V}$, and $\mathrm{Mn}$ atoms with the typical $\mathrm{U}=4 \mathrm{eV}$ value. The specific $\mathrm{U}$ value does not change the predicted magnetic ordering nor the easy axis determination $[49,50]$. The cutoff kinetic energy for plane waves was set to $600 \mathrm{eV}$. Considering the van der Waals interaction between layers, the Becke-Jonson attenuation DFT + D3 method was performed for empirical correction.

A vacuum spacing of $20 \AA$ along the $\mathrm{M}^{\prime} \mathrm{MCO}_{2}$ normal was used to avoid the interactions caused by the periodic boundary condition. The Brillouin zone (BZ) was sampled using $11 \times 11 \times 1 \Gamma$-centered, k-point Monkhorst-Pack grids for the calculations of relaxation and electronic structures for NM, FM, and AFM1 primitive cells. Additionally, k-mesh was decreased to $6 \times 12 \times 1$ for $2 \times 1 \times 1$ AFM2 and AFM3 supercells. In the static self-consistent calculation, k-point grid sampling of $20 \times 20 \times 1$ was used for the primitive cell, and k-point grid sampling of $12 \times 24 \times 1$ was used for the $2 \times 1 \times 1$ supercell. 


\section{Results}

\subsection{Stable Structures of Janus MXenes}

The monolayer $\mathrm{M}_{2} \mathrm{C}$ MXene is a centered honeycomb structure with P3m1 symmetry, in which the $2 \mathrm{D}$ hexagonal $\mathrm{C}$ atom is sandwiched between two hexagonal $\mathrm{M}$ atoms. There are four possible configurations for $\mathrm{O}$ atoms absorbed on the $\mathrm{M}$ atom [51]: (a) $\mathrm{O}$ atoms located right above the $\mathrm{M}$ atoms (top sites); (b) $\mathrm{O}$ atoms located at the hollow sites of adjacent $\mathrm{C}$ atoms (hcp sites); (c) $\mathrm{O}$ atoms located at the hollow sites of contralateral $\mathrm{M}$ atoms (fcc sites); (d) on the one side, $\mathrm{O}$ atoms are at fcc sites, and on the other side, $\mathrm{O}$ atoms are at the hcp sites. According to previous research by Tan [52] and Wang [53], (b) configuration is stable for $\mathrm{CrMnCO}_{2}$ and $\mathrm{Cr}_{2} \mathrm{CO}_{2}$ and (c) configuration is stable for $\mathrm{VCrCO}_{2}$, $\mathrm{VMnCO}_{2}, \mathrm{~V}_{2} \mathrm{CO}_{2}$, and $\mathrm{Mn}_{2} \mathrm{CO}_{2}$. So, we selected those configurations for the following calculations. Figure 1 shows the structures of symmetric $\mathrm{V}_{2} \mathrm{CO}_{2}, \mathrm{Cr}_{2} \mathrm{CO}_{2}$, and $\mathrm{Mn}_{2} \mathrm{CO}_{2}$. The arrangement of atoms observed from the top and bottom is the same. Figure 2 shows the structures of Janus $\mathrm{MXenes} \mathrm{VCrCO}_{2}, \mathrm{VMnCO}_{2}$, and $\mathrm{CrMnCO}_{2}$. It can be seen that the arrangement of atoms seen from the top and bottom is different, so the symmetry of $\mathrm{VCrCO}_{2}, \mathrm{VMnCO}_{2}$, and $\mathrm{CrMnCO}_{2}$ is lower than that of $\mathrm{V}_{2} \mathrm{CO}_{2}, \mathrm{Cr}_{2} \mathrm{CO}_{2}$, and $\mathrm{Mn}_{2} \mathrm{CO}_{2}$, which is consistent with the symmetry of their space group. The basic information of their lattice parameters is shown in Table 1.

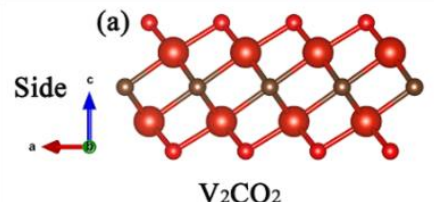

(b)

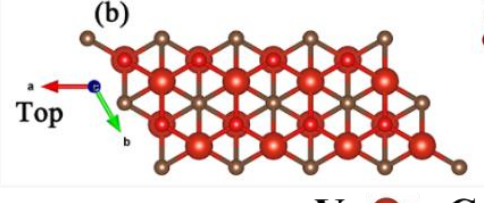

(c)

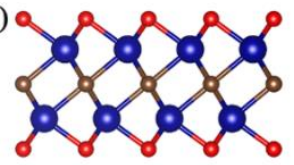

$\mathrm{Cr}_{2} \mathrm{CO}_{2}$

(d)

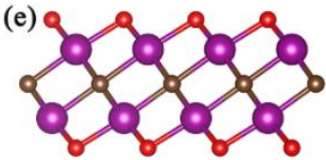

$\mathrm{Mn}_{2} \mathrm{CO}_{2}$

V

$\mathrm{Cr}$
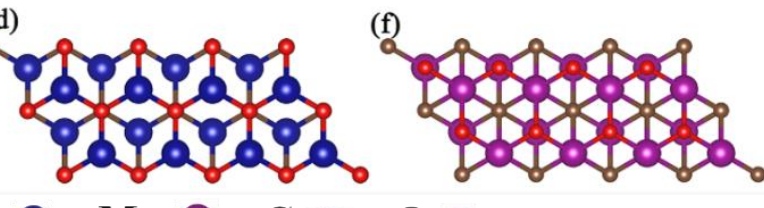

O

Figure 1. $\mathrm{V}_{2} \mathrm{CO}_{2}, \mathrm{Cr}_{2} \mathrm{CO}_{2}$, and $\mathrm{Mn}_{2} \mathrm{CO}_{2}$ structures: $(\mathbf{a}, \mathbf{c}, \mathbf{e})$ and $(\mathbf{b}, \mathbf{d}, \mathbf{f})$ are the side and top views of $\mathrm{V}_{2} \mathrm{CO}_{2}, \mathrm{Cr}_{2} \mathrm{CO}_{2}$, and $\mathrm{Mn}_{2} \mathrm{CO}_{2}$ structures, respectively.
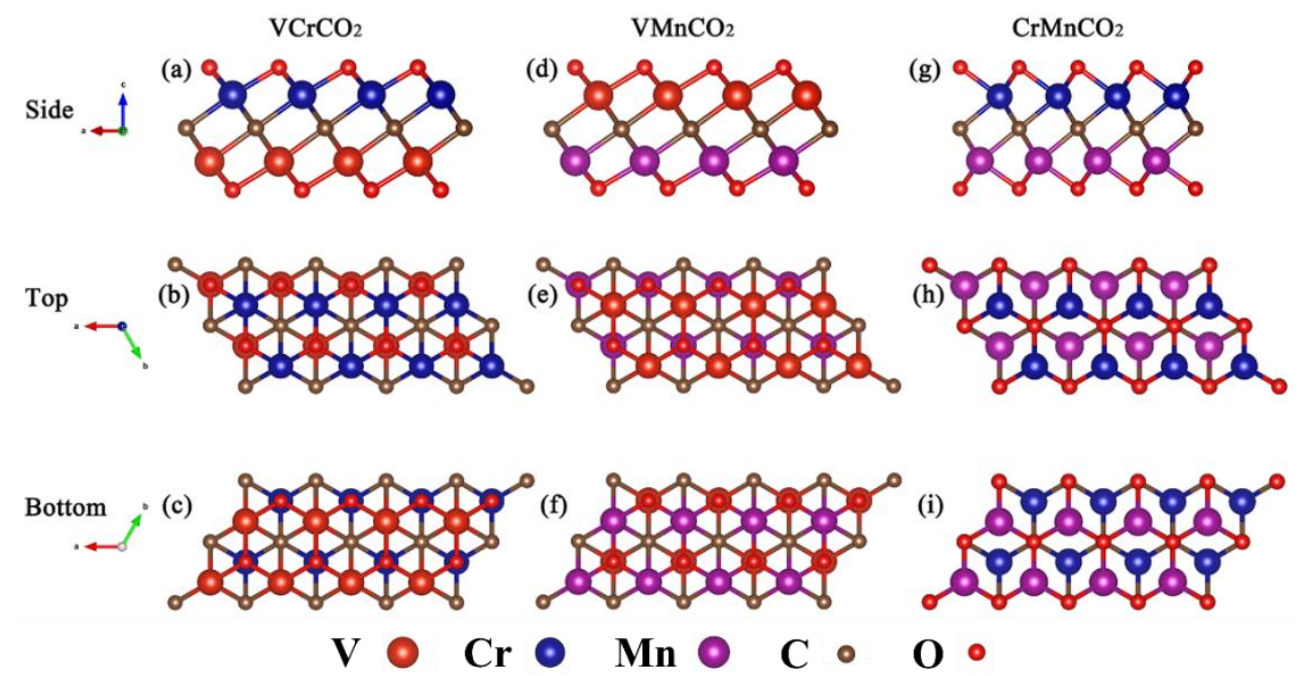

Figure 2. $\mathrm{VCrCO}_{2}, \mathrm{VMnCO}_{2}$, and $\mathrm{CrMnCO}_{2}$ structures: $(\mathbf{a}, \mathbf{d}, \mathbf{g})$ and $(\mathbf{b}, \mathbf{e}, \mathbf{h})$ and $(\mathbf{c}, \mathbf{f}, \mathbf{i})$ are the side, top, and bottom views of $\mathrm{VCrCO}_{2}, \mathrm{VMnCO}_{2}$, and $\mathrm{CrMnCO}_{2}$ structures, respectively. 
Table 1. The lattice parameters of $\mathrm{M}^{\prime} \mathrm{MCO}_{2}$.

\begin{tabular}{ccccccc}
\hline & $\mathbf{V C r C O}_{2}$ & $\mathrm{VMnCO}_{2}$ & $\mathrm{CrMnCO}_{\mathbf{2}}$ & $\mathbf{V}_{\mathbf{2}} \mathbf{C O}_{\mathbf{2}}$ & $\mathbf{C r}_{\mathbf{2}} \mathbf{C O}_{\mathbf{2}}$ & $\mathbf{M n}_{\mathbf{2}} \mathbf{C O}_{\mathbf{2}}$ \\
\hline Symmetry & $\mathrm{P} 3 \mathrm{~m} 1$ & $\mathrm{P} 3 \mathrm{~m} 1$ & $\mathrm{P} 3 \mathrm{~m} 1$ & $\mathrm{P} 3 \mathrm{~m} 1$ & $\mathrm{P} 3 \mathrm{~m} 1$ & $\mathrm{P} 3 \mathrm{~m} 1$ \\
Group & $\left(\mathrm{C}_{3 \mathrm{~V}-1}\right)$ & $\left(\mathrm{C}_{3 \mathrm{~V}-1}\right)$ & $\left(\mathrm{C}_{3 \mathrm{~V}-1}\right)$ & $\left(\mathrm{D}_{3 \mathrm{~d}-3}\right)$ & $\left(\mathrm{D}_{3 \mathrm{~d}-3}\right)$ & $\left(\mathrm{D}_{3 \mathrm{~d}-3}\right)$ \\
a $\AA$ & 2.88 & 2.89 & 2.66 & 2.88 & 2.68 & 2.87 \\
$\mathrm{~b} / \AA$ & 2.88 & 2.89 & 2.66 & 2.88 & 2.68 & 2.87 \\
$\mathrm{c} / \AA$ & 21.81 & 21.81 & 21.81 & 21.81 & 21.81 & 21.81 \\
$\alpha$ & $90^{\circ}$ & $90^{\circ}$ & $90^{\circ}$ & $90^{\circ}$ & $90^{\circ}$ & $90^{\circ}$ \\
$\beta$ & $90^{\circ}$ & $90^{\circ}$ & $90^{\circ}$ & $90^{\circ}$ & $90^{\circ}$ & $90^{\circ}$ \\
$\gamma$ & $120^{\circ}$ & $120^{\circ}$ & $120^{\circ}$ & $120^{\circ}$ & $120^{\circ}$ & $120^{\circ}$ \\
\hline
\end{tabular}

Many compounds of $\mathrm{V}, \mathrm{Cr}$, and $\mathrm{Mn}$ are magnetic [39]. We calculated the total energy of the non-spin-polarized system and the spin-polarized system, respectively, by using standard DFT method: the result is shown in Table 2. It can be seen that, except $\mathrm{V}_{2} \mathrm{CO}_{2}$, the total energy of the spin polarization is lower than that of the non-spin polarization. When taking spin polarization into account, obvious magnetic moment can be observed in magnetic atoms. Therefore, the ground states of $\mathrm{VCrCO}_{2}, \mathrm{VMnCO}_{2}, \mathrm{CrMnCO}_{2}, \mathrm{Cr}_{2} \mathrm{CO}_{2}$, and $\mathrm{Mn}_{2} \mathrm{CO}_{2}$ must be magnetic, while the ground state of $\mathrm{V}_{2} \mathrm{CO}_{2}$ is NM. Although the ground states of $\mathrm{V}_{2} \mathrm{CO}_{2}$ are $\mathrm{NM}$, the difference between the $\mathrm{NM}$ and the magnetic state is very small (about $0.0002 \mathrm{eV}$ ). When considering the spin polarization in the system, the $\mathrm{V}$ atom has about $1 \mu \mathrm{B}$ /atom sized magnetic moment. Under certain conditions, NM may become magnetic, so it is necessary to study its magnetic properties.

Table 2. Total energy of spin-polarized and non-spin-polarized systems. NM stands for non-spinpolarized system, magnetic stands for spin-polarized systems, the unit of total energy is eV/u.c (unit cell).

\begin{tabular}{ccccccc}
\hline & $\mathrm{VCrCO}_{2}$ & $\mathrm{VMnCO}_{\mathbf{2}}$ & $\mathbf{C r M n C O}_{\mathbf{2}}$ & $\mathbf{V}_{\mathbf{2}} \mathbf{C O}_{\mathbf{2}}$ & $\mathbf{C r}_{\mathbf{2}} \mathbf{C O}_{\mathbf{2}}$ & $\mathbf{M n}_{\mathbf{2}} \mathbf{C O}_{\mathbf{2}}$ \\
\hline $\mathrm{NM}$ & -44.322 & -42.926 & -42.488 & $-45.597(5)$ & -43.804 & -40.701 \\
Magnetic & -44.502 & -43.451 & -42.499 & $-45.597(3)$ & -43.882 & -41.431 \\
\hline
\end{tabular}

Considering the magnetism of the TM atoms, we employed the FM and AFM order for each $\mathrm{M}^{\prime} \mathrm{MCO}_{2}$ configuration, as shown in Figure 3. For FM configurations, the magnetic moments of $\mathrm{M}$ atoms are parallel, while for AFM configurations, the magnetic moments are antiparallel with each other. According to the different coupling kinds between atoms, we constructed three different AFM configurations, named AFM1, AFM2, and AFM3. AFM1 configuration is characterized by intralayer FM coupling and interlayer AFM coupling; AFM2 configuration is characterized by intralayer AFM coupling and interlayer FM coupling; AFM3 configuration is characterized by AFM coupling of atoms both intralayer and interlayer. The initial models of NM, FM, and AFM configurations are completely the same, but due to the different coupling models of magnetic atoms, after structure optimization, different configurations will have different lattice parameters, total energy, electronic structure, and other aspects. Compared to the initial models, the lattice constants of NM hardly change, while the corresponding FM and AFM are slight increased. Meanwhile, FM and AFM configurations symmetries are also reduced, which is related to the coupling between magnetic atoms after spin polarization, as shown in Tables S1-S6. 
(a)

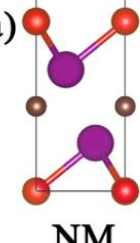

(b)

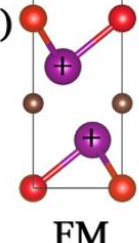

(c)

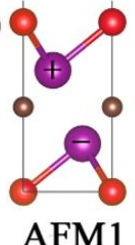

(d)

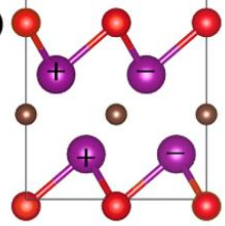

AFM2 (e)

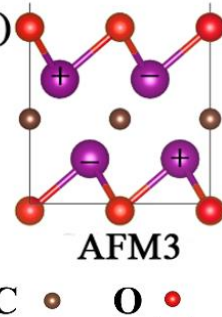

Figure 3. $\mathrm{M}^{\prime} \mathrm{MCO}_{2}$ magnetic state configurations: (a-e) represent NM, FM, AFM1, AFM2, and AFM3 configurations, respectively. In $\mathrm{M}^{\prime}$ /M atoms, " + " represents spin-up and “-“ represents spin-down.

\subsection{Magnetic Properties}

The spin polarization can be corrected by adopting the DFT + U method, but it will introduce additional situ coulomb interaction energy. However, $U$ is not added in the case of the non-spin-polarized system, which means that the total energy of the two system do not have comparability. Therefore, in the following analysis, we study the electronic structures and magnetic properties of the ground states of $\mathrm{VCrCO}_{2}, \mathrm{VMnCO}_{2}, \mathrm{CrMnCO}_{2}, \mathrm{~V}_{2} \mathrm{CO}_{2}$, $\mathrm{Cr}_{2} \mathrm{CO}_{2}$, and $\mathrm{Mn}_{2} \mathrm{CO}_{2}$ configurations under spin polarization, regardless of NM. The calculated total energy is shown in Table 3. The coupling effect between magnetic configurations is different, making the corresponding energy and other properties different. The total energy difference between different magnetic states is very small, which means that the ground states of AFM and FM are unstable in a specific environment. For each $\mathrm{M}^{\prime} \mathrm{MCO}_{2}$ configuration, the configuration with the lowest energy is its most stable configuration state- the magnetic ground state; moreover, this is the focus of the present analysis and study. From the value, we can obtain that the magnetic ground states of $\mathrm{VCrCO}_{2}, \mathrm{VMnCO}_{2}$, and $\mathrm{Cr}_{2} \mathrm{CO}_{2}$ are $\mathrm{FM}$, and that the ground state energies are $-37.321 \mathrm{eV} /$ u.c, $-36.936 \mathrm{eV} /$ u.c, and $-35.488 \mathrm{eV} /$ u.c, respectively. The magnetic ground state of $\mathrm{CrMnCO}_{2}$ is $\mathrm{AFM} 3$, and the ground state energy is $-35.707 \mathrm{eV} /$ u.c. The ground state of $\mathrm{V}_{2} \mathrm{CO}_{2}$ is $\mathrm{NM}$, the magnetic ground state is AFM1, and the magnetic ground state energy is $-38.020 \mathrm{eV} /$ u.c. The magnetic ground state of $\mathrm{Mn}_{2} \mathrm{CO}_{2}$ is AFM2, and the ground state energy is $-35.989 \mathrm{eV} /$ u.c. In previous studies on the magnetic properties of MXenes, Mohammad Khazaei [35] and Tan [54] calculated the magnetic ground state of $\mathrm{Cr}_{2} \mathrm{CO}_{2}$ as $\mathrm{FM}$, while $\mathrm{Hu}$ [32] obtained the magnetic ground state of $\mathrm{V}_{2} \mathrm{CX}_{2}(\mathrm{X}=\mathrm{F}, \mathrm{OH})$ as AFM. The conclusion of these studies is consistent with our calculated results. Additionally, we can conclude that, when replacing TM atoms, symmetric MXenes $\mathrm{V}_{2} \mathrm{CO}_{2}, \mathrm{Cr}_{2} \mathrm{CO}_{2}$, and $\mathrm{Mn}_{2} \mathrm{CO}_{2}$ become Janus $\mathrm{MXenes} \mathrm{VCrCO}_{2}$, $\mathrm{VMnCO}_{2}$, and $\mathrm{CrMnCO}_{2}$, respectively; the magnetic ground states will change, and Janus MXenes can regulate the magnetic ground states.

Table 3. The total energy of FM and AFM structures of $\mathrm{M}^{\prime} \mathrm{MCO}_{2}$, the unit of total energy is eV/u.c (unit cell).

\begin{tabular}{ccccc}
\hline & FM & AFM1 & AFM2 & AFM3 \\
\hline $\mathrm{VCrCO}_{2}$ & -37.321 & -37.215 & -37.223 & -37.223 \\
$\mathrm{VMnCO}_{2}$ & -36.936 & -36.921 & -36.921 & -36.886 \\
$\mathrm{CrMnCO}_{2}$ & -34.778 & -34.349 & -34.743 & -35.707 \\
$\mathrm{~V}_{2} \mathrm{CO}_{2}$ & -38.013 & -38.020 & -37.911 & -37.918 \\
$\mathrm{Cr}_{2} \mathrm{CO}_{2}$ & -35.488 & -34.794 & -35.263 & -35.365 \\
$\mathrm{Mn}_{2} \mathrm{CO}_{2}$ & -35.934 & -35.913 & -35.989 & -35.746 \\
\hline
\end{tabular}


The magnetic moments of all magnetic configurations of each $\mathrm{M}^{\prime} \mathrm{MCO}_{2}$ are summarized in Tables S7-S12. Additionally, we drew the curves of the magnetic moments under different magnetic configurations and $\mathrm{M}^{\prime} \mathrm{MCO}_{2}$ configurations, as shown in Figure 4. From the contribution of atomic species to the magnetic moments, we can find that the magnetic moments of $\mathrm{C}$ and $\mathrm{O}$ are close to 0 and the magnetic moment is mainly contributed by the $\mathrm{TM}$ atoms $\mathrm{V}, \mathrm{Cr}$, and $\mathrm{Mn}$. In addition, the curves satisfied $\mu(\mathrm{Mn})>\mu(\mathrm{Cr})>\mu(\mathrm{V})$ because of the different electron numbers- $\mathrm{Mn}$ has one more electron than $\mathrm{Cr}$, and $\mathrm{Cr}$ has one more electron than $\mathrm{V}$. In the FM configurations, the order of total magnetic moment is $\mu\left(\mathrm{Mn}_{2} \mathrm{CO}_{2}\right)$ $>\mu\left(\mathrm{MnCrCO}_{2}\right)>\mu\left(\mathrm{Cr}_{2} \mathrm{CO}_{2}\right)>\mu\left(\mathrm{VMnCO}_{2}\right) \mu\left(\mathrm{VCrCO}_{2}\right)>\mu\left(\mathrm{V}_{2} \mathrm{CO}_{2}\right)$. The large the specific gravity of $\mathrm{Mn}$ in the configuration, the greater the net magnetic moment; the large the specific gravity of $\mathrm{V}$, the smaller the net magnetic moment, which agrees with $\mu(\mathrm{Mn})>$ $\mu(\mathrm{Cr})>\mu(\mathrm{V})$. Because the magnetic moment of $\mathrm{V}$ atom is small, when the TM atom in MXene is $\mathrm{V}$, the stable configuration tends to be nonmagnetic. This means that the ground state of $\mathrm{V}_{2} \mathrm{CO}_{2}$ is nonmagnetic, while the ground states of $\mathrm{VCrCO}_{2}, \mathrm{VMnCO}_{2}, \mathrm{CrMnCO}_{2}$, $\mathrm{Cr}_{2} \mathrm{CO}_{2}$, and $\mathrm{Mn}_{2} \mathrm{CO}_{2}$ are magnetic. As the magnetic order changes, the magnetic moments of $\mathrm{V}, \mathrm{Cr}$, and $\mathrm{Mn}$ have little change, and it basically maintains a horizontal trend within the range of $0.50 \mu \mathrm{B}$. It indicates that the type of TM atom is a decisive factor for the magnetic moment; moreover, the environment of atoms and the coupling mode between atoms have little effect on the magnetic moment.

(a)

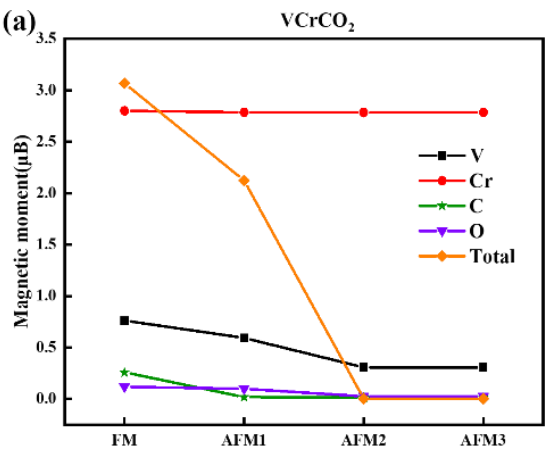

(c)

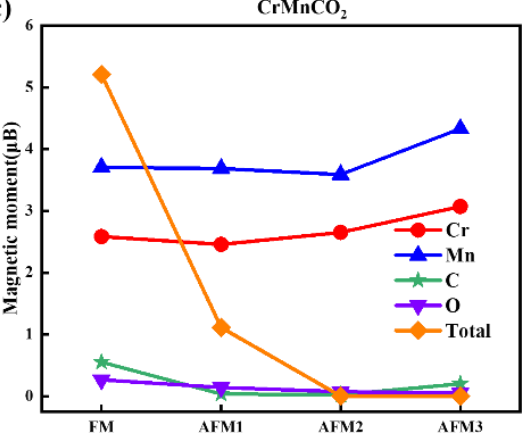

(e)

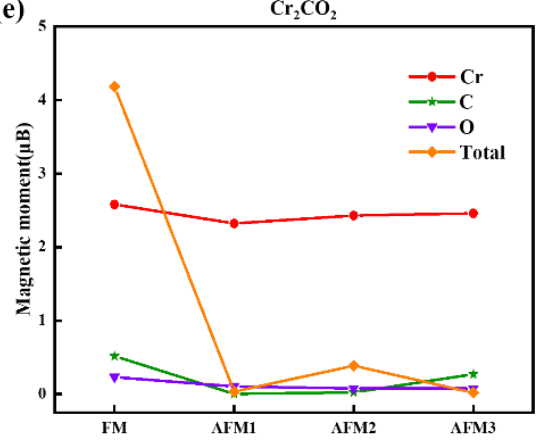

(b)

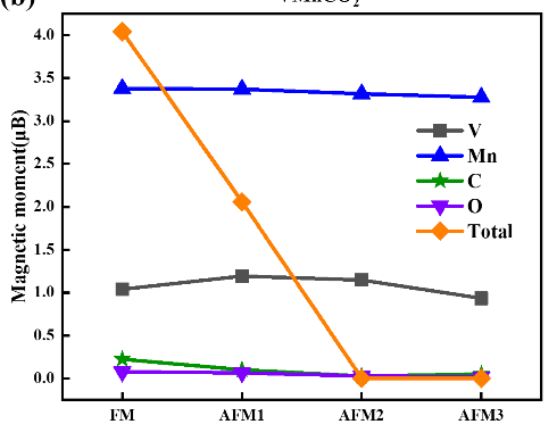

(d)

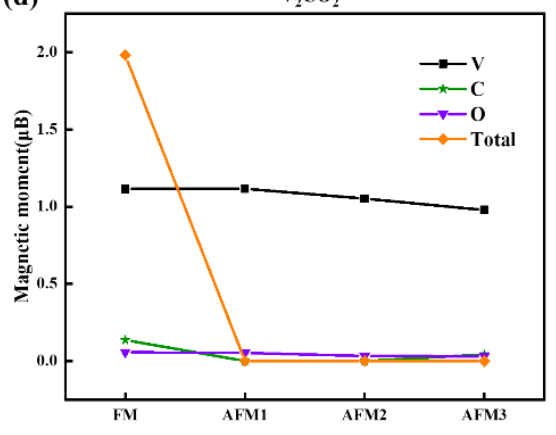

(f)

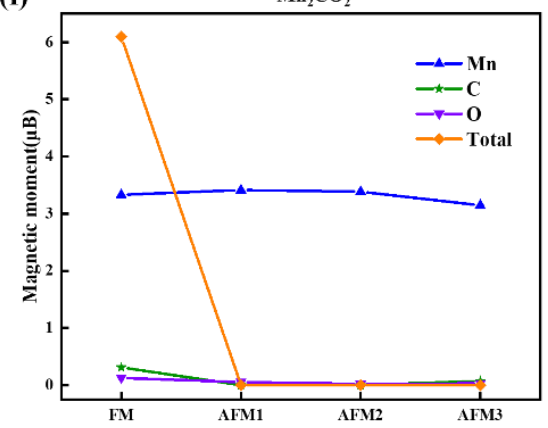

Figure 4. Magnetic moment curves under different $\mathrm{M}^{\prime} \mathrm{MCO}_{2}$ configurations. (a) $\mathrm{VCrCO}_{2}$ configuration; (b) $\mathrm{VMnCO}_{2}$ configuration; (c) $\mathrm{CrMnCO}_{2}$ configuration; (d) $\mathrm{V}_{2} \mathrm{CO}_{2}$ configuration; (e) $\mathrm{Cr}_{2} \mathrm{CO}_{2}$ configuration; (f) $\mathrm{Mn}_{2} \mathrm{CO}_{2}$ configuration. 
Meanwhile, the total net magnetic moment is greatly affected by the magnetic configuration. It is clear that FM shows obvious magnetic moment, in which the magnetic moment of magnetic atoms is in the same direction. The total magnetic moment is similar to the algebraic sum of magnetic moments of magnetic atoms, so it has a large magnetic moment output. As for AFM1, Janus MXenes show obvious magnetic moment, while the net magnetic moment of symmetric MXenes is almost 0 . Given that the intralayer atoms are composed of FM coupling, the different magnetic moments of the top and bottom atoms cannot completely cancel the Janus MXene; therefore, it has net magnetic moments and exhibits ferromagnetism. In contrast to the symmetric MXenes with the same top and bottom atoms, the magnetic moment can be completely cancelled out, so the net magnetic moment is 0 and it exhibits anti-ferromagnetism. The net magnetic moments of AFM2 and AFM3 are almost 0 , a value which does not show magnetic moment externally. The reason is that both the intralayer coupling is AFM and the adjacent electrons have opposite spin directions, which causes the net magnetic moment of top and bottom layers to be 0 , a value which does not show magnetic moment externally. We discover that the higher the symmetry of the magnetic moment, the lower the total energy, and the more stable this configuration will be. Besides, there is modulation between different TM atoms in Janus MXenes. When $\mathrm{V}$ atoms are replaced with $\mathrm{Cr}$ in $\mathrm{V}_{2} \mathrm{CO}_{2}$, the magnetic moment of the $\mathrm{V}$ atoms becomes smaller; meanwhile, when $\mathrm{Mn}$ atoms are replaced with $\mathrm{Cr}$ in $\mathrm{Mn}_{2} \mathrm{CO}_{2}$, the magnetic moment of the $\mathrm{Mn}$ atoms becomes large-the modulation effects of $\mathrm{Cr}$ atoms on $\mathrm{V}_{2} \mathrm{CO}_{2}$ and $\mathrm{Mn}_{2} \mathrm{CO}_{2}$ are different. As for the $\mathrm{Cr}_{2} \mathrm{CO}_{2}$ configuration, replacing the $\mathrm{Cr}$ atoms with $\mathrm{V}$ or $\mathrm{Mn}$ all will cause the magnetic moment of the $\mathrm{Cr}$ atoms to become large. Therefore, we conclude that Janus MXenes can manipulate the size of magnetic moment.

\subsection{Electronic Properties}

For the above magnetic ground states, we further explored their electronic properties, and calculated their band structures and densities of state (DOS), respectively. Figure 5 shows the band structures of each $\mathrm{M}^{\prime} \mathrm{MCO}_{2}$. Additionally, we found that the spin-up and spin-down curves of $\mathrm{Mn}_{2} \mathrm{CO}_{2}, \mathrm{CrMnCO}_{2}$, and $\mathrm{V}_{2} \mathrm{CO}_{2}$ almost completely coincide, which is consistent with AFM configurations; while the spin-up and spin-down curves of $\mathrm{VCrCO}_{2}, \mathrm{VMnCO}_{2}$, and $\mathrm{Cr}_{2} \mathrm{CO}_{2}$ split, which are almost the only spin-up curves near the Fermi level-this finding is consistent with FM configurations. Therefore, we found that the configuration of $\mathrm{Mn}_{2} \mathrm{CO}_{2}, \mathrm{CrMnCO}_{2}$, and $\mathrm{V}_{2} \mathrm{CO}_{2}$ are $\mathrm{FM}$, and the configuration of $\mathrm{VCrCO}_{2}, \mathrm{VMnCO}_{2}$, and $\mathrm{Cr}_{2} \mathrm{CO}_{2}$ are $\mathrm{FM}$.

As for $\mathrm{M}^{\prime} \mathrm{MCO}_{2}$ with AFM configurations, near the Fermi level, the valence band and the conduction band of $\mathrm{Mn}_{2} \mathrm{CO}_{2}$ are clearly separated, and no band curve crosses the Fermi level. Moreover, the top valence band is near the point $\mathrm{M}(0.622)$, and the bottom conduction band is near the point $\mathrm{K}(1.358)$, illustrating that $\mathrm{Mn}_{2} \mathrm{CO}_{2}$ is an indirect band gap semiconductor, a finding that is in keeping with the results of Zhou [55]. Meanwhile, both $\mathrm{CrMnCO}_{2}$ and $\mathrm{V}_{2} \mathrm{CO}_{2}$ have band curves crossing the Fermi level, and their top valence band and bottom conduction band are located at the point $\Gamma$, with a small band gap width, showing metallic character. With regard to $\mathrm{M}^{\prime} \mathrm{MCO}_{2}$, with FM configurations, it can be seen from Figure 5a,b,e that the red curves (spin-down) are distributed on both sides of the Fermi level, with large band gap widths, while the blue curves (spin-up) are densely distributed, crossing the Fermi level. The electronic states with spin-up make the band gap narrow-these are metallic materials. On the whole, we concluded that, when $\mathrm{M}$ is replaced with $\mathrm{M}^{\prime}$ - causing non-Janus MXene to become Janus MXene-the band gap width was greatly reduced and the conductivity became better; therefore, Janus MXenes can regulate the band gap. 

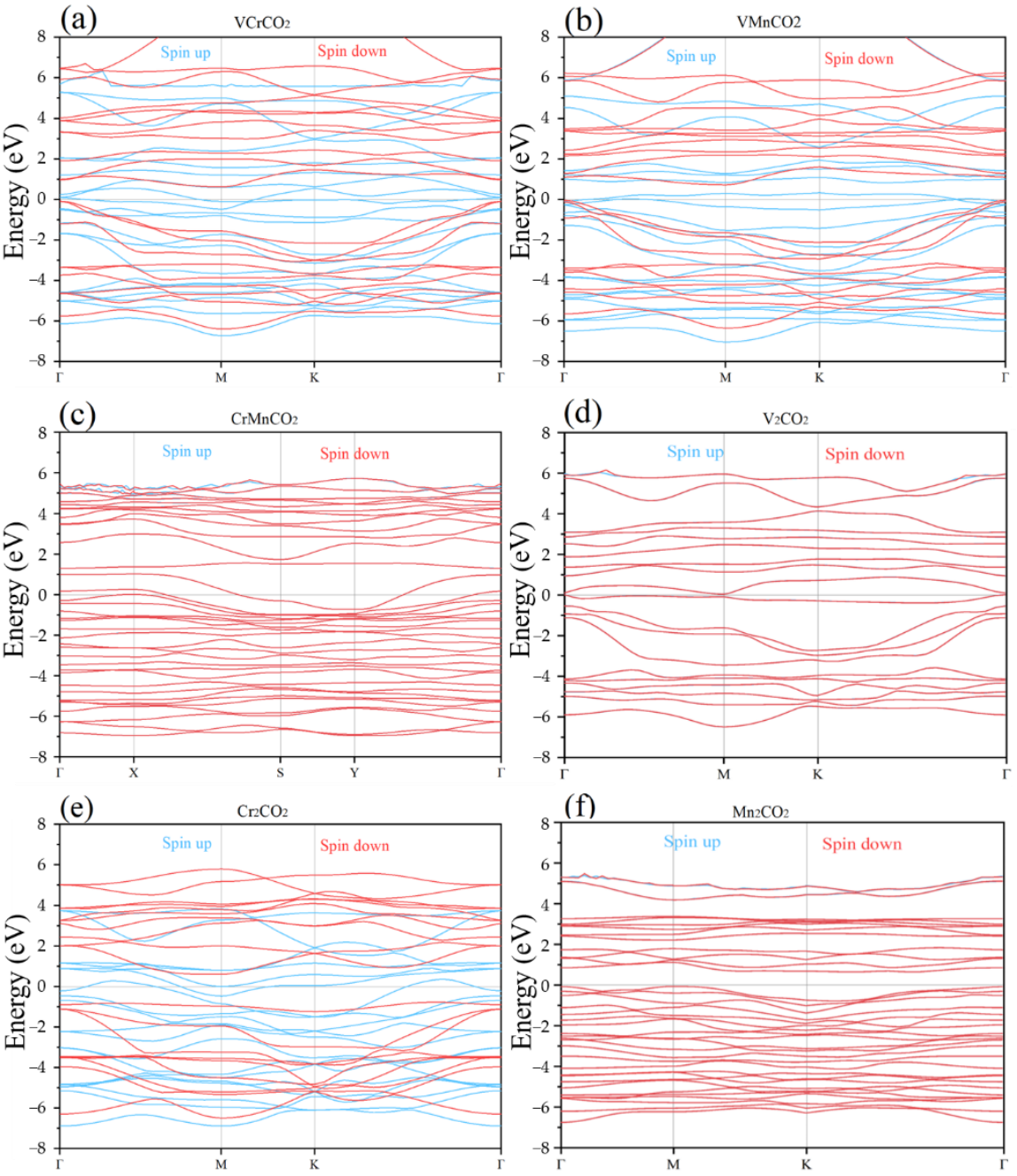

Figure 5. The band gap of $\mathrm{M}^{\prime} \mathrm{MCO}_{2}$. (a) $\mathrm{VCrCO}_{2} ;(\mathbf{b}) \mathrm{VMnCO}_{2} ;$ (c) $\mathrm{CrMnCO}_{2} ;(\mathbf{d}) \mathrm{V}_{2} \mathrm{CO}_{2} ;$ (e) $\mathrm{Cr}_{2} \mathrm{CO}_{2}$; (f) $\mathrm{Mn}_{2} \mathrm{CO}_{2}$.

To facilitate the description of the modulation action of Janus MXenes, we plotted the density of state (DOS) of the magnetic ground state of $\mathrm{M}^{\prime} \mathrm{MCO}_{2}$, as shown in Figure 6. There are a large number of electrons near the Fermi level for $\mathrm{VCrCO}_{2}, \mathrm{VMnCO}_{2}, \mathrm{CrMnCO}_{2}$, $\mathrm{V}_{2} \mathrm{CO}_{2}$, and $\mathrm{Cr}_{2} \mathrm{CO}_{2}$, indicating that they have metallic properties. However, there are almost no electrons at the Fermi level for $\mathrm{Mn}_{2} \mathrm{CO}_{2}$, which can be considered as the forbidden band, and the band width is $0.7071 \mathrm{eV}$, indicating that it is a semiconductor. In addition, we found that the PDOS of the $\mathrm{d}$ orbitals of $\mathrm{V}, \mathrm{Cr}$, and Mn contributed most of the TDOS. For symmetric MXenes, the PDOS of d orbitals of $\mathrm{V}, \mathrm{Cr}$, and $\mathrm{Mn}$ are almost consistent with the TDOS of $\mathrm{V}_{2} \mathrm{CO}_{2}, \mathrm{Cr}_{2} \mathrm{CO}_{2}$, and $\mathrm{Mn}_{2} \mathrm{CO}_{2}$ in the energy range of $-1 \sim 4 \mathrm{eV},-3 \sim 6 \mathrm{eV}$, and $2 \sim 6 \mathrm{eV}$, respectively. Meanwhile, for Janus MXenes, the TDOS are the synergy of d orbitals of different TM atoms. The d orbitals of the $\mathrm{V}$ atoms contributed most of the electrons in the following energy ranges: $0 \sim 2 \mathrm{eV}$ for $\mathrm{VCrCO}_{2} ;-1 \sim 2 \mathrm{eV}$ and $4 \sim 6 \mathrm{eV}$ for $\mathrm{VMnCO}_{2}$. The $\mathrm{d}$ orbitals of the $\mathrm{Cr}$ atoms contributed most of the electrons in the following energy ranges: $-2 \sim 0 \mathrm{eV}$ and $2 \sim 6 \mathrm{eV}$ for $\mathrm{VCrCO}_{2},-3 \sim 4 \mathrm{eV}$ for $\mathrm{CrMnCO}_{2}$. The $\mathrm{d}$ orbitals of the Mn atoms contributed most of the electrons in the following energy ranges: $-6 \sim-1 \mathrm{eV}$ and $2 \sim 4 \mathrm{eV}$ for $\mathrm{VMnCO}_{2}$, and $-5 \sim-3 \mathrm{eV}$ and $4 \sim 6 \mathrm{eV}$ for $\mathrm{CrMnCO}_{2}$. The sum of the d orbitals of $\mathrm{V}, \mathrm{Cr}$, and $\mathrm{Mn}$ is almost equal to the TDOS, showing that the magnetism of the system is mainly derived from the $\mathrm{d}$ orbital electrons of magnetic atoms. 

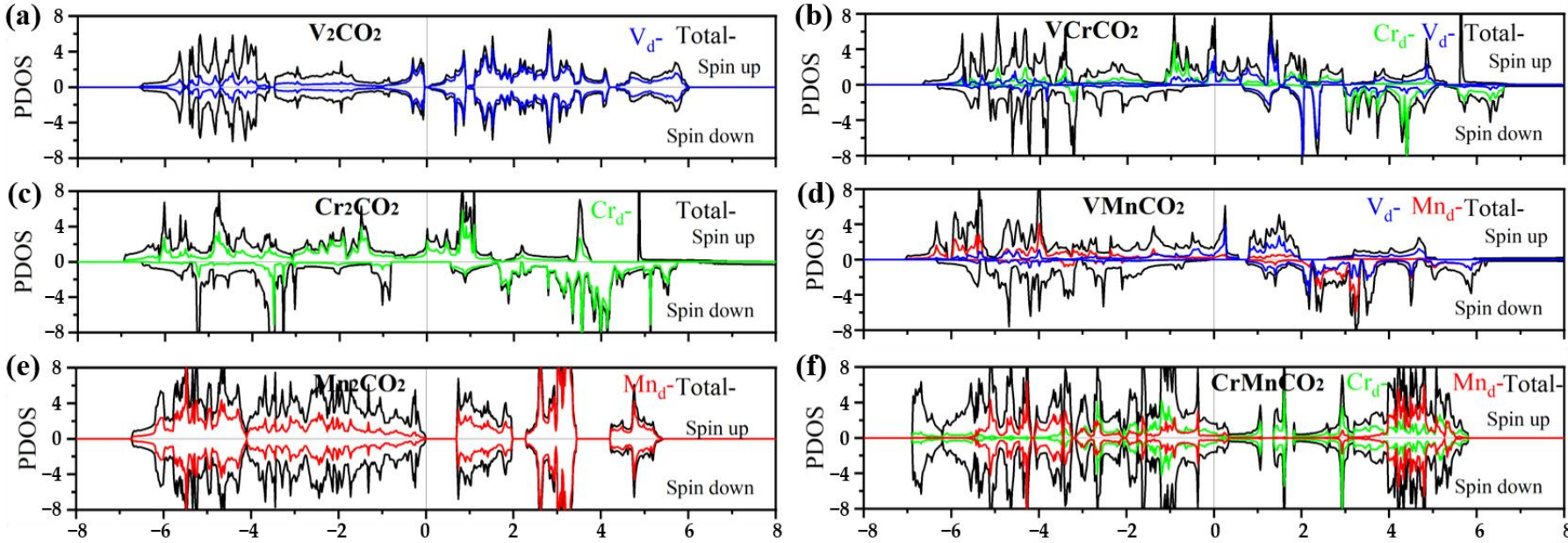

Figure 6. DOS of $\mathrm{M}^{\prime} \mathrm{MCO}_{2}$

(a) $\mathrm{V}_{2} \mathrm{CO}_{2}$

(b) $\mathrm{VCrCO}_{2}$

(c) $\mathrm{Cr}_{2} \mathrm{CO}_{2}$;

(d) $\mathrm{VMnCO}_{2}$;

(e) $\mathrm{Mn}_{2} \mathrm{CO}_{2}$ (f) $\mathrm{CrMnCO}_{2}$.

Since the magnetic moment of the system is proportional to the area integral of the upper and lower curves, the greater the difference between the spin-up and spin-down, the greater the split, and the greater the net magnetic moment. The upper curves and lower curves of $\mathrm{V}_{2} \mathrm{CO}_{2}$ and $\mathrm{Mn}_{2} \mathrm{CO}_{2}$ are nearly symmetric and the net magnetic moment is almost 0 , which is consistent with the magnetic ground state of AFM. The magnetic ground state of $\mathrm{Cr}_{2} \mathrm{CO}_{2}$ is $\mathrm{FM}$, and its upper and lower curves have a certain split, where the peak position energy of the upper curve is lower, and the peak position energy of the lower curve is higher. The area integral of DOS of the upper curve and the lower curve is close, within the energy range of $-7 \sim-3 \mathrm{eV}$, the spin-up electron state occupies the dominant position in the range of $-3 \sim 2 \mathrm{eV}$, and the spin-down electron state occupies the dominant position in the range of $2 \sim 6 \mathrm{eV}$, which causes the $\mathrm{FM}$ configuration to have $4.184 \mu \mathrm{B} /$ atom net magnetic moment.

When a $\mathrm{V}$ atom in $\mathrm{V}_{2} \mathrm{CO}_{2}$ is replaced by $\mathrm{Cr}$ or Mn atoms-becoming Janus MXene $\mathrm{VCrCO}_{2}$ or $\mathrm{VMnCO}_{2}$, with the magnetic ground state becoming $\mathrm{FM}$ - the upper and lower curves are clearly split. The main electron state is spin-up in the range of $-2 \sim 2 \mathrm{eV}$ and spin-down in the range of $2 \sim 6 \mathrm{eV}$. Below $-2 \mathrm{eV}$, the peak of spin-up moves to low energy and the peak of spin-down moves to high energy. When a $\mathrm{Cr}$ atom is replaced with an $\mathrm{Mn}$ atom in $\mathrm{Cr}_{2} \mathrm{CO}_{2}$ - becoming Janus $\mathrm{MXene} \mathrm{CrMnCO}_{2}$, with the magnetic ground state becoming AFM3 - the upper and lower curves are symmetric and the net magnetic moment is 0 . In conclusion, we can judge the magnetic configuration of a system by the magnetic moment of the atoms, the energy band, and the DOS. Janus MXenes can regulate the band gap width, the magnetic ground state, and the net magnetic moment; this is a great adjusting method.

\section{Conclusions}

We investigated the magnetic properties and electron structures of $\mathrm{M}^{\prime} \mathrm{MCO}_{2}$ with different magnetic configurations. The following results were found: the magnetic ground states of $\mathrm{VCrCO}_{2}, \mathrm{VMnCO}_{2}$, and $\mathrm{Cr}_{2} \mathrm{CO}_{2}$ are $\mathrm{FM}$; the magnetic ground state of $\mathrm{CrMnCO}_{2}$ is AFM2; the magnetic ground state of $\mathrm{Mn}_{2} \mathrm{CO}_{2}$ is AFM2; the magnetic ground state of $\mathrm{V}_{2} \mathrm{CO}_{2}$ is AFM1 and its ground state is NM. The band gap widths of $\mathrm{VCrCO}_{2}, \mathrm{VMnCO}_{2}$, $\mathrm{CrMnCO}_{2}, \mathrm{~V}_{2} \mathrm{CO}_{2}$, and $\mathrm{Cr}_{2} \mathrm{CO}_{2}$ are no more than $0.02 \mathrm{eV}$, showing metallic properties; meanwhile, $\mathrm{Mn}_{2} \mathrm{CO}_{2}$ is a semiconductor, with a $0.7071 \mathrm{eV}$ band gap width. Moreover, we determined the magnetic configuration of the systems through the magnetic moment, the energy band, and the DOS. Further analysis showed that Janus MXenes can adjust the band gap, magnetic ground state, and output net magnetic moment, resulting in smaller band gap widths and better electrical conductivities when compared with corresponding 
materials. These theoretical results provide guidance for further experimental verification and electronic device application.

Supplementary Materials: The following are available online at https:/ / www.mdpi.com/article / 10.3390/nano12030556/s1, Tables S1-S6: the lattice parameters of $\mathrm{VCrCO}_{2}, \mathrm{VMnCO}_{2}, \mathrm{CrMnCO}_{2}$, $\mathrm{V}_{2} \mathrm{CO}_{2}, \mathrm{Cr}_{2} \mathrm{CO}_{2}$, and $\mathrm{Mn}_{2} \mathrm{CO}_{2}$, Tables S7-S12: the magnetic moment of $\mathrm{VCrCO}_{2}, \mathrm{VMnCO}_{2}, \mathrm{CrMnCO}_{2}$, $\mathrm{V}_{2} \mathrm{CO}_{2}, \mathrm{Cr}_{2} \mathrm{CO}_{2}$, and $\mathrm{Mn}_{2} \mathrm{CO}_{2}$.

Author Contributions: The study was planned and designed by P.G. and P.Q. DFT calculations were performed by P.G. and M.S. The manuscript was prepared by P.G., M.S., X.W., Q.L., S.H., and Y.S. All authors discussed the results and commented on the manuscript together. All authors have read and agreed to the published version of the manuscript.

Funding: This research was funded by National Key Research and Development Program of China(2021YFB3802100), National Natural Science Foundation of China (Grant No.51971031), National Natural Science Foundation of China (51801010), Guangdong Province Key Area R\&D Program (2019B010940001), and Guangdong Provincial Key Laboratory of Meta-RF Microwave.

Data Availability Statement: The datasets generated during and/or analyzed during the current study are available from the corresponding author.

Conflicts of Interest: The authors declare no conflict of interest.

\section{References}

1. Novoselov, K.S.; Geim, A.K.; Morozov, S.V.; Jiang, D.; Katsnelson, M.I.; Grigorieva, I.V.; Dubonos, S.V.; Firsov, A.A. Twodimensional gas of massless Dirac fermions in graphene. Nature 2005, 438, 197-200. [CrossRef] [PubMed]

2. Zhang, Y.; Tan, Y.W.; Stormer, H.L.; Kim, P. Experimental observation of the quantum Hall effect and Berry's phase in graphene. Nature 2005, 438, 201-204. [CrossRef]

3. Novoselov, K.S.; Geim, A.K.; Morozov, S.V.; Jiang, D.; Zhang, Y.; Dubonos, S.V.; Grigorieva, I.V.; Firsov, A.A. Electric field in atomically thin carbon films. Science 2004, 306, 666-669. [CrossRef]

4. VahidMohammadi, A.; Rosen, J.; Gogotsi, Y. The world of two-dimensional carbides and nitrides (MXenes). Science 2021, 372, 6547. [CrossRef] [PubMed]

5. Shekhirev, M.; Shuck, C.E.; Sarycheva, A.; Gogotsi, Y. Characterization of MXenes at every step, from their precursors to single flakes and assembled films. Prog. Mater. Sci. 2021, 120, 100757. [CrossRef]

6. Ahsan, M.A.; He, T.; Eid, K.; Abdullah, A.M.; Sanad, M.F.; Aldalbahi, A.; Alvarado-Tenorio, B.; Du, A.; Puente Santiago, A.R.; Noveron, J.C. Controlling the Interfacial Charge Polarization of MOF-Derived 0D-2D vdW Architectures as a Unique Strategy for Bifunctional Oxygen Electrocatalysis. ACS Appl. Mater. Interfaces 2022, 14, 3919-3929. [CrossRef]

7. Naguib, M.; Kurtoglu, M.; Presser, V.; Lu, J.; Niu, J.; Heon, M.; Hultman, L.; Gogotsi, Y.; Barsoum, M.W. Two-dimensional nanocrystals produced by exfoliation of Ti 3AlC 2. Adv. Mater. 2011, 23, 4248-4253. [CrossRef]

8. Naguib, M.; Mochalin, V.N.; Barsoum, M.W.; Gogotsi, Y. 25th anniversary article: MXenes: A new family of two-dimensional materials. Adv. Mater. 2014, 26, 992-1005. [CrossRef]

9. $\mathrm{Hu}, \mathrm{T} . ; \mathrm{Li}, \mathrm{Z} . ; \mathrm{Hu}, \mathrm{M} . ;$ Wang, J.; Hu, Q.; Li, Q.; Wang, X. Chemical Origin of Termination-Functionalized MXenes: Ti3C2T2 as a Case Study. J. Phys. Chem. C 2017, 121, 19254-19261. [CrossRef]

10. Li, L. Lattice dynamics and electronic structures of Ti3C2O2 and Mo2TiC2O2 (MXenes): The effect of Mo substitution. Comput. Mater. Sci. 2016, 124, 8-14. [CrossRef]

11. Mashtalir, O.; Naguib, M.; Mochalin, V.N.; Dall'Agnese, Y.; Heon, M.; Barsoum, M.W.; Gogotsi, Y. Intercalation and delamination of layered carbides and carbonitrides. Nat. Commun. 2013, 4, 1716. [CrossRef] [PubMed]

12. Ren, S.; Feng, R.; Cheng, S.; Wang, Q.; Zheng, Z. Synergistic Catalytic Acceleration of MXene/MWCNTs as Decorating Materials for Ultrasensitive Detection of Morphine. Electroanalysis 2021, 33, 1471-1483. [CrossRef]

13. Feng, X.; Yu, Z.; Long, R.; Li, X.; Shao, L.; Zeng, H.; Zeng, G.; Zuo, Y. Self-assembling 2D/2D (MXene/LDH) materials achieve ultra-high adsorption of heavy metals Ni2+ through terminal group modification. Sep. Purif. Technol. 2020, 253, 117525. [CrossRef]

14. Hantanasirisakul, K.; Gogotsi, Y. Electronic and Optical Properties of 2D Transition Metal Carbides and Nitrides (MXenes). Adv. Mater. 2018, 30, 1804779. [CrossRef] [PubMed]

15. Jiang, X.; Kuklin, A.V.; Baev, A.; Ge, Y.; Ågren, H.; Zhang, H.; Prasad, P.N. Two-dimensional MXenes: From morphological to optical, electric, and magnetic properties and applications. Phys. Rep. 2020, 848, 1-58. [CrossRef]

16. Xia, F.; Wang, H.; Xiao, D.; Dubey, M.; Ramasubramaniam, A. Two-dimensional material nanophotonics. Nat. Photonics 2014, 8, 899-907. [CrossRef]

17. Yao, H.; Zhang, C.; Wang, Q.; Li, J.; Yu, Y.; Xu, F.; Wang, B.; Wei, Y. Novel two-dimensional layered mosi2z4 (Z = p, as): New promising optoelectronic materials. Nanomaterials 2021, 11, 559. [CrossRef] 
18. Shah, S.A.A.; Sayyad, M.H.; Khan, K.; Sun, J.; Guo, Z. Application of mxenes in perovskite solar cells: A short review. Nanomaterials 2021, 11, 2151. [CrossRef]

19. Wyatt, B.C.; Rosenkranz, A.; Anasori, B. 2D MXenes: Tunable Mechanical and Tribological Properties. Adv. Mater. 2021, 33, 2007973. [CrossRef]

20. Fiori, G.; Bonaccorso, F.; Iannaccone, G.; Palacios, T.; Neumaier, D.; Seabaugh, A.; Banerjee, S.K.; Colombo, L. Electronics based on two-dimensional materials. Nat. Nanotechnol. 2014, 9, 768-779. [CrossRef]

21. Li, J.S.; Wang, Y.; Liu, C.H.; Li, S.L.; Wang, Y.G.; Dong, L.Z.; Dai, Z.H.; Li, Y.F.; Lan, Y.Q. Coupled molybdenum carbide and reduced graphene oxide electrocatalysts for efficient hydrogen evolution. Nat. Commun. 2016, 7, 11204. [CrossRef] [PubMed]

22. Pandey, M.; Thygesen, K.S. Two-Dimensional MXenes as Catalysts for Electrochemical Hydrogen Evolution: A Computational Screening Study. J. Phys. Chem. C 2017, 121, 13593-13598. [CrossRef]

23. Liu, A.; Liang, X.; Ren, X.; Guan, W.; Gao, M.; Yang, Y.; Yang, Q.; Gao, L.; Li, Y.; Ma, T. Recent Progress in MXene-Based Materials: Potential High-Performance Electrocatalysts. Adv. Funct. Mater. 2020, 30, 2003437. [CrossRef]

24. Nguyen, V.H.; Nguyen, B.S.; Hu, C.; Nguyen, C.C.; Nguyen, D.L.T.; Dinh, M.T.N.; Vo, D.V.N.; Trinh, Q.T.; Shokouhimehr, M.; Hasani, A.; et al. Novel architecture titanium carbide (Ti3C2Tx) mxene cocatalysts toward photocatalytic hydrogen production: A mini-review. Nanomaterials 2020, 10, 602. [CrossRef] [PubMed]

25. Yang, J.; Zhang, S.; Wang, A.; Wang, R.; Wang, C.K.; Zhang, G.P.; Chen, L. High magnetoresistance in ultra-thin two-dimensional Cr-based MXenes. Nanoscale 2018, 10, 19492-19497. [CrossRef] [PubMed]

26. Bonaccorso, F.; Colombo, L.; Yu, G.; Stoller, M.; Tozzini, V.; Ferrari, A.C.; Ruoff, R.S.; Pellegrini, V. Graphene, related twodimensional crystals, and hybrid systems for energy conversion and storage. Science 2015, 347, 1246501. [CrossRef] [PubMed]

27. Wu, X.; Wang, Z.; Yu, M.; Xiu, L.; Qiu, J. Stabilizing the MXenes by Carbon Nanoplating for Developing Hierarchical Nanohybrids with Efficient Lithium Storage and Hydrogen Evolution Capability. Adv. Mater. 2017, 29, 1607017. [CrossRef]

28. Shinde, P.; Patil, A.; Lee, S.C.; Jung, E.; Jun, S.C. Two-dimensional MXenes for electrochemical energy storage applications. J. Mater. Chem. A 2022, 10, 1105-1149. [CrossRef]

29. Pan, J.; Lany, S.; Qi, Y. Computationally Driven Two-Dimensional Materials Design: What Is Next? ACS Nano 2017, 11, 7560-7564 [CrossRef]

30. Frey, N.C.; Wang, J.; Vega Bellido, G.I.; Anasori, B.; Gogotsi, Y.; Shenoy, V.B. Prediction of Synthesis of 2D Metal Carbides and Nitrides (MXenes) and Their Precursors with Positive and Unlabeled Machine Learning. ACS Nano 2019, 13, 3031-3041. [CrossRef]

31. Lee, Y.; Cho, S.B.; Chung, Y.C. Tunable indirect to direct band gap transition of monolayer Sc $2 \mathrm{CO}_{2}$ by the strain effect. ACS Appl. Mater. Interfaces 2014, 6, 14724-14728. [CrossRef]

32. $\mathrm{Hu}, \mathrm{J} . ; \mathrm{Xu}, \mathrm{B}$;; Ouyang, C.; Yang, S.A.; Yao, Y. Investigations on V2C and V2CX2 (X= F, OH) monolayer as a promising anode material for Li Ion batteries from first-principles calculations. J. Phys. Chem. C 2014, 118, 24274-24281. [CrossRef]

33. Xie, Y.; Kent, P.R.C. Hybrid density functional study of structural and electronic properties of functionalized Tin +1 Xn $(X=C$, N) monolayers. Phys. Rev. B-Condens. Matter Mater. Phys. 2013, 87, 235441. [CrossRef]

34. Si, C.; Zhou, J.; Sun, Z. Half-Metallic Ferromagnetism and Surface Functionalization-Induced Metal-Insulator Transition in Graphene-like Two-Dimensional Cr2C Crystals. ACS Appl. Mater. Interfaces 2015, 7, 17510-17515. [CrossRef]

35. Khazaei, M.; Arai, M.; Sasaki, T.; Chung, C.Y.; Venkataramanan, N.S.; Estili, M.; Sakka, Y.; Kawazoe, Y. Novel electronic and magnetic properties of two-dimensional transition metal carbides and nitrides. Adv. Funct. Mater. 2013, 23, 2185-2192. [CrossRef]

36. Li, F.; Wei, W.; Zhao, P.; Huang, B.; Dai, Y. Electronic and Optical Properties of Pristine and Vertical and Lateral Heterostructures of Janus MoSSe and WSSe. J. Phys. Chem. Lett. 2017, 8, 5959-5965. [CrossRef]

37. Yang, Q.; Tan, C.; Meng, R.; Jiang, J.; Liang, Q.; Sun, X.; Yang, D.; Chen, X. The intriguing electronic and optical properties modulation of hydrogen and fluorine codecorated silicene layers. Appl. Surf. Sci. 2017, 398, 73-80. [CrossRef]

38. Lu, A.Y.; Zhu, H.; Xiao, J.; Chuu, C.P.; Han, Y.; Chiu, M.H.; Cheng, C.C.; Yang, C.W.; Wei, K.H.; Yang, Y.; et al. Janus monolayers of transition metal dichalcogenides. Nat. Nanotechnol. 2017, 12, 744-749. [CrossRef]

39. Frey, N.C.; Bandyopadhyay, A.; Kumar, H.; Anasori, B.; Gogotsi, Y.; Shenoy, V.B. Surface-Engineered MXenes: Electric Field Control of Magnetism and Enhanced Magnetic Anisotropy. ACS Nano 2019, 13, 2831-2839. [CrossRef]

40. He, J.; Lyu, P.; Sun, L.Z.; Morales García, Á.; Nachtigall, P. High temperature spin-polarized semiconductivity with zero magnetization in two-dimensional Janus MXenes. J. Mater. Chem. C 2016, 4, 6500-6509. [CrossRef]

41. Kresse, G.; Furthmüller, J. Efficient iterative schemes for ab initio total-energy calculations using a plane-wave basis set. Phys. Rev. B-Condens. Matter Mater. Phys. 1996, 54, 11169. [CrossRef]

42. Joubert, D. From ultrasoft pseudopotentials to the projector augmented-wave method. Phys. Rev. B-Condens. Matter Mater. Phys. 1999, 59, 1758-1775. [CrossRef]

43. Perdew, J.P.; Chevary, J.A.; Vosko, S.H.; Jackson, K.A.; Pederson, M.R.; Singh, D.J.; Fiolhais, C. Atoms, molecules, solids, and surfaces: Applications of the generalized gradient approximation for exchange and correlation. Phys. Rev. B 1992, $46,6671$. [CrossRef]

44. Perdew, J.P.; Wang, Y. Accurate and simple analytic representation of the electron-gas correlation energy. Phys. Rev. B 1992, 45, 13244. [CrossRef] [PubMed]

45. Blöchl, P.E. Projector augmented-wave method. Phys. Rev. B 1994, 50, 17953-17979. [CrossRef] [PubMed]

46. Hubbard, J. Electron correlations in narrow energy bands. Proc. R. Soc. Lond. Ser. A Math. Phys. Sci. 1963, 276, 238-257. [CrossRef] 
47. Jain, A.; Hautier, G.; Ong, S.P.; Moore, C.J.; Fischer, C.C.; Persson, K.A.; Ceder, G. Formation enthalpies by mixing GGA and GGA + U calculations. Phys. Rev. B-Condens. Matter Mater. Phys. 2011, 84, 045115. [CrossRef]

48. Zhou, F.; Cococcioni, M.; Marianetti, C.A.; Morgan, D.; Ceder, G. First-principles prediction of redox potentials in transition-metal compounds with LDA + U. Phys. Rev. B-Condens. Matter Mater. Phys. 2004, 70, 1-8. [CrossRef]

49. Kumar, H.; Frey, N.C.; Dong, L.; Anasori, B.; Gogotsi, Y.; Shenoy, V.B. Tunable Magnetism and Transport Properties in Nitride MXenes. ACS Nano 2017, 11, 7648-7655. [CrossRef]

50. Frey, N.C.; Kumar, H.; Anasori, B.; Gogotsi, Y.; Shenoy, V.B. Tuning Noncollinear Spin Structure and Anisotropy in Ferromagnetic Nitride MXenes. ACS Nano 2018, 12, 6319-6325. [CrossRef] [PubMed]

51. Chen, Z.; Huang, S.; Huang, B.; Wan, M.; Zhou, N. Transition metal atoms implanted into MXenes (M2CO2) for enhanced electrocatalytic hydrogen evolution reaction. Appl. Surf. Sci. 2020, 509, 145319. [CrossRef]

52. Tan, Z.; Fang, Z.; Li, B.; Yang, Y. First-Principles Study of the Ferromagnetic Properties of Cr2CO2and Cr2NO2MXenes. ACS Omega 2020, 5, 25848-25853. [CrossRef] [PubMed]

53. Wang, X.; Wang, C.; Ci, S.; Ma, Y.; Liu, T.; Gao, L.; Qian, P.; Ji, C.; Su, Y. Accelerating 2D MXene catalyst discovery for the hydrogen evolution reaction by computer-driven workflow and an ensemble learning strategy. J. Mater. Chem. A 2020, 8, 23488-23497. [CrossRef]

54. Tan, C.; Cao, X.; Wu, X.J.; He, Q.; Yang, J.; Zhang, X.; Chen, J.; Zhao, W.; Han, S.; Nam, G.H.; et al. Recent Advances in Ultrathin Two-Dimensional Nanomaterials. Chem. Rev. 2017, 117, 6225-6331. [CrossRef] [PubMed]

55. Zhou, Y.; Zu, X. Mn2C sheet as an electrode material for lithium-ion battery: A first-principles prediction. Electrochim. Acta 2017, 235, 167-174. [CrossRef] 